\title{
Serum caspase-9 levels are increased in patients with amyotrophic lateral sclerosis
}

\author{
Joanna Iłżecka
}

Received: 15 November 2010/Accepted: 21 October 2011/Published online: 3 November 2011

(C) The Author(s) 2011. This article is published with open access at Springerlink.com

\begin{abstract}
It is known that apoptosis may play a role in the pathophysiology of amyotrophic lateral sclerosis (ALS). Moreover, caspase-9 is implicated in the apoptosis pathway. The aim of the study was to investigate caspase- 9 levels in serum of patients with ALS. The study involved 30 patients with ALS and 30 patients from the control group. The serum caspase-9 levels were measured using the enzyme-linked immunosorbent method. The study showed that caspase- 9 levels are significantly increased in serum of the patients with ALS comparing to the control group $(p<0.05)$. There was a significant correlation of serum caspase-9 levels with severity of clinical state of ALS patients and duration of the disease $(p<0.05)$. The results indicate that caspase-9 may be implicated in pathomechanism of neurodegeneration in ALS.
\end{abstract}

Keywords Amyotrophic lateral sclerosis - Apoptosis · Caspase-9 · Neurodegeneration · Pathomechanisms · Serum

\section{Introduction}

Amyotrophic lateral sclerosis (ALS) is a progressive neurodegenerative disease affecting motor neurons. Apoptosis mediates programmed natural death of neurons and is a physiologically important process in neurogenesis. However, premature apoptosis and/or an aberration in apoptosis regulation may be implicated in the pathogenesis of neurodegeneration in different neurological diseases, including

J. Iłżecka $(\bowtie)$

Department of Neurological Rehabilitation, Medical University, ul. Chodźki 6, 20-093 Lublin, Poland

e-mail: ilzecka@onet.pl
ALS [1]. Mitochondria play a key role in the apoptotic process. Among the two of the signaling pathways of apoptosis, i.e., the "extrinsic" and the "intrinsic" pathways, the latter is assumed to initiate in mitochondria. Its activation involves the release of cytochrome $\mathrm{c}$ and other pro-apoptotic factors from the mitochondrial intermembrane space. In the cytosol, cytochrome c binds to the apoptosis protease activation factor (APAf-1) and forms a complex indicated as "apoptosome." The complexinduced activation of pro-caspase- 9 initiates an enzymatic reaction cascade leading to the execution of apoptosis in cells [2]. Caspase-9 is a member of caspase family of cysteine proteases. Activated caspase-9 cleaves downstream caspases such as caspase- $3,-6$, and -7 initiating the caspase cascade [3].

Data from the literature showed that apoptosis may play a role in pathomechanism of ALS and degeneration of motor neurons in this disease [4, 5]. Hetz et al. [6] demonstrated that the proapoptotic Bcl-2 family member Bcl-2-interacting mediator of cell death (BIM) mediates motoneuron loss in a model of ALS. The apoptosis markers, including caspase-9, are activated in the ventral horn of motor neurons in a transgenic mouse model of ALS [7, 8]. According to Guégan et al. [9] the mitochondrial-dependent programmed cell death pathway, including the redistribution of Bax, the cytosolic release of cytochrome c, and the activation of caspase-9, is recruited during neurodegeneration in spinal cords of transgenic SOD1 mouse model of ALS. It was also observed that the G93A mutant SOD1 interaction with DNA might induce DNA damage and trigger the apoptotic response by activating p53. This toxic activity of mutant SOD1 in the nucleus may play an important role in the complex mechanisms associated with motor neuron death observed in ALS pathogenesis [10]. The extracellular nucleotides mediate neuronal apoptosis 
via pathways involving C-jun N-terminal kinase 1 (JNK1), extracellular signal-regulated kinase (ERK), and caspases 8/9/3 [11]. The balance between anti- and pro-apoptotic proteins related to endoplasmic reticulum (ER) stress is impaired from the pre-symptomatic stage in this ALS mouse model, and this imbalance may be related to the pathogenesis of motor neuron degeneration in ALS [12].

Inoue et al. [13] examined the effects of inhibition of X chromosome-linked inhibitor of apoptosis (XIAP), a mammalian inhibitor of caspase-3, -7, and -9. It was observed that XIAP attenuated disease progression without delaying onset. The authors suggest that caspase-9 plays a crucial role in progression of ALS and constitutes a promising therapeutic target. Thus, apoptosis contributes to pathology in ALS, and appropriate anti-apoptosis therapy might therefore be beneficial in this disease [14].

Although caspase-9 is an intracellular protein, it was suggested that serum markers of apoptosis may be noninvasive biomarkers in patients [15]. Moreover, data from the literature shows that measurement of caspases in serum could be useful in monitoring different diseases [16-19]. The aim of the study was to measure serum caspase-9 levels in patients with ALS and to investigate whether there is a relationship of this caspase with clinical parameters of the disease.

\section{Materials and methods}

Thirty ALS patients took part in the study. The ALS was diagnosed according to the El Escorial criteria of ALS [20]. There were 23 patients with clinically definite ALS (the presence of upper motor neuron as well as lower motor neuron signs in the bulbar region and at least two spinal regions, or the presence of upper motor neuron signs in two spinal regions and lower motor neuron signs in three spinal regions) and 7 patients with clinically probable ALS [upper motor neuron and lower motor neuron signs in at least two regions with some upper motor neuron signs rostral to (above) the lower motor neuron signs] according to these criteria. The clinical condition of the patients was measured by the revised version of Amyotrophic Lateral Sclerosis Functional Rating Scale [ALSFRS-R] [21]. According to this scale the ALS patients scored from 0 to 39 points. They were divided into two subgroups: patients with a mild clinical state (over 24 points according to ALSFRS-R) and patients with a severe clinical state (up to 24 points according to ALSFRS-R). The patients with the ALS were also divided according to the type of the disease onset (patients with a limb-onset and patients with a bulbar-onset). The average duration of ALS was 16 months (3 months-7 years). According to the duration of the disease, the two subgroups of patients were isolated (patients with a short duration of ALS $\leq 12$ months and patients with a long duration of ALS $>12$ months). All patients with ALS had nutritional deficiencies. The restriction of food consumption, malnutrition, and weight loss was observed because of progressive weakening of the muscles and dysphagia.

The control group consisted of 30 patients with tensiontype headache. The patients from the control group were recruited out of hospitalized patients and that is why healthy persons were not included in the study. The patients from control group were admitted to the hospital because of acute headache occurred and it was necessary to exclude subarachnoid hemorrhage. The characteristics of patients are presented in Table 1 .

The study was approved by the Ethics Committee of Medical University and performed in accordance with the ethical standards established in Helsinki.

Serum samples were collected into the plastic tubes, centrifuged rapidly, and stored at $-70^{\circ} \mathrm{C}$ until the analysis was performed. Caspase- 9 levels were measured by the enzyme-linked immunosorbent method using the commercial ELISA kit for human Caspase-9 (Bender MedSystems, Austria) in accordance with the manufacturer's instructions. The nonparametric Mann-Whitney rank sum test was used to examine the differences between the groups because data was not normally distributed. The correlation analysis was performed using the Spearman rank correlation. The caspase- 9 values are expressed in $\mathrm{ng} / \mathrm{mL}$, as median and range. $P$ values $<0.05$ were considered significant.

\section{Results}

The study showed that the caspase-9 levels are significantly increased in the serum of the whole group of patients with ALS [5.4 (0.0-32.2) ng/mL] compared with those from the control group [2.65 $(0.0-14.3) \mathrm{ng} / \mathrm{mL}](p<0.05)$. Caspase-9 levels were still significantly increased in ALS patients with long duration of the disease, with severe

Table 1 Characteristics of patients

\begin{tabular}{llll}
\hline Group & $\begin{array}{l}\text { No. of } \\
\text { patients }\end{array}$ & $\begin{array}{l}\text { Age } \\
\text { (years) }\end{array}$ & $\begin{array}{l}\text { Male/ } \\
\text { female }\end{array}$ \\
\hline Control & 30 & $50 \pm 7$ & $15 / 15$ \\
ALS: total & 30 & $54 \pm 6$ & $17 / 13$ \\
ALS: short duration & 16 & $54 \pm 3$ & $9 / 7$ \\
ALS: long duration & 14 & $54 \pm 8$ & $8 / 6$ \\
ALS: bulbar onset & 12 & $60 \pm 7$ & $4 / 8$ \\
ALS: limb onset & 18 & $50 \pm 5$ & $13 / 5$ \\
ALS: mild clinical state & 14 & $49 \pm 2$ & $9 / 5$ \\
ALS: severe clinical state & 16 & $57 \pm 6$ & $8 / 8$ \\
\hline
\end{tabular}


clinical state, and with bulbar onset of ALS compared with controls $(p<0.05)$ but not in ALS patients with short duration of the disease, with mild clinical state and with limb onset of ALS compared with controls $(p>0.05)$. The difference in the serum caspase- 9 levels between subgroups of ALS patients according to the division of their type of ALS onset, severity of clinical state, and duration of the disease was not significant $(p>0.05)$.

The median values of the serum caspase- 9 levels, and a comparative analysis between subgroups are presented in Fig. 1 and in Table 2 .

The correlation between serum caspase- 9 and severity of clinical state of ALS patients (ALSFRS-R score) and duration of the disease was statistically significant ( $r=0.61, p=0.01$ and $r=0.48, p=0.03$; respectively).

There was no significant difference between of the age of patients in ALS and controls $(p=0.47)$. There were also no significant differences between the age of male and female in patients with ALS and controls $(p=0.35$ and $p=0.28$; respectively).

The difference of serum caspase-9 levels between ALS male and female, and between younger ( $\leq 55$ years) and older ( $>55$ years) patients with ALS was not significant ( $p=0.61$ and $p=0.14$; respectively).

\section{Discussion}

There is evidence that apoptosis and activation of caspase9 play a role in different neurological diseases.

Darwish et al. [22] showed that activated caspase-9 and cytochrome $\mathrm{c}$ are present in the cerebrospinal fluid (CSF) of patients with severe traumatic brain injury.
Caspase-9 plays an important role in the development of multiple sclerosis (MS). It was suggested that polymorphisms in the caspase- 9 gene may influence the activity of the disease [23].

According to $\mathrm{Yu}$ et al. [24], chronic extrinsic cervical spinal cord compression leads to Fas-mediated apoptosis of neurons and oligodendrocytes which is associated with activation of caspase- $8,-9$, and -3 and progressive neurological deficits.

Spinal and bulbar muscular atrophy (SBMA) is a motor neuron disease caused by polyglutamine expansion mutation in the androgen receptor (AR). Ranganathan et al. [25] showed that the mutant protein in $\mathrm{MN}-1$ cells resulted in increased Bax, caspase- 9 , and caspase- 3 .

The pilocarpine-induced status epilepticus (SE) results in massive degenerative death of neuronal cells in brains. The degenerating neurons, most of them also expressing apoptosis signalling molecules such as caspase-9 and activated caspase-3 [26].

Blandini et al. [27] measured the activity of proapoptotic caspase-3 and -9 in peripheral blood lymphocytes (PBLs) of Parkinson Disease (PD) and Alzheimer Disease (AD) patients. Marked increases in caspase-3 and -9 activity were found.

Presenilin 1 (PS1) gene mutations are the major causes of early onset familial AD. Acceleration of apoptosis, elevation of caspase-3/7 activity, and significant increases in caspase-4, -8 , and -9 activities during apoptosis induced by several agents were found in the mutant PS1-transfected cells [28].

It has been postulated that the pathogenesis of PD is associated with mitochondrial dysfunction. Rotenone caused the loss of mitochondrial membrane potential,
Fig. 1 Serum caspase-9 level in patients with ALS and control $(p=0.03)$
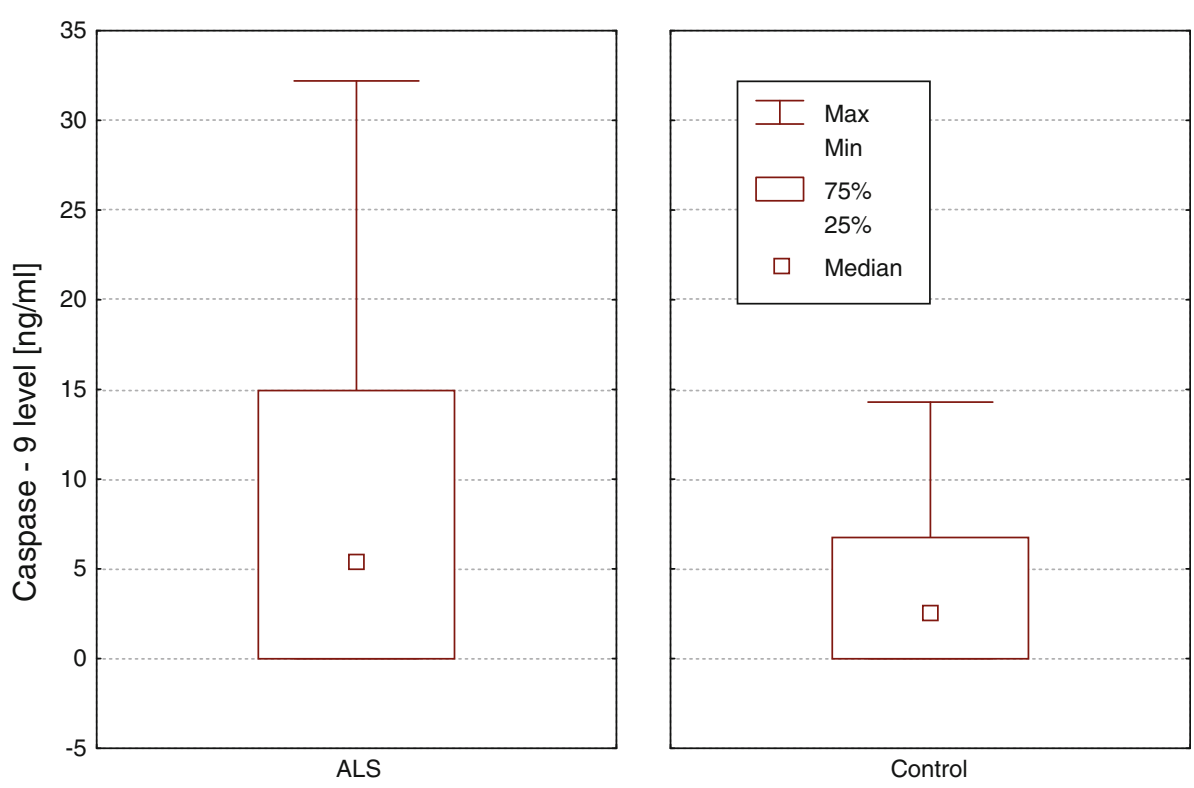
Table 2 Serum caspase-9 levels in patients with ALS and a comparative analysis between groups

\begin{tabular}{lcl}
\hline Group & Caspase-9 level (ng/ml); median and range & Comparison \\
\hline ALS: short duration & $4.9(0.0-25.4)$ & Control versus ALS: short duration $p=0.16$ \\
ALS: long duration & $9.25(0.0-32.2)$ & Control versus ALS: long duration $p=0.03^{*}$ \\
& & ALS short versus long duration $p=0.31$ \\
ALS: bulbar onset & $8.0(0.0-23.7)$ & Control versus ALS: bulbar onset $p=0.04^{*}$ \\
ALS: limb onset & $4.90(0.0-32.2)$ & Control versus ALS: limb onset $p=0.13$ \\
& $3.9(0.0-15.7)$ & ALS bulbar versus limb onset $p=0.59$ \\
ALS: mild clinical state & $8.8(0-32.2)$ & Control versus ALS: mild clinical state $p=0.33$ \\
ALS: severe clinical state & & Control versus ALS: severe clinical state $p=0.01 *$ \\
& & ALS mild versus severe clinical state $p=0.11$ \\
\hline
\end{tabular}

Data is expressed as median and range. Mann-Whitney rank sum test

* $p$ statistically significant, at least $p<0.05$

released cytochrome $\mathrm{c}$ into the cytosol, reduced cytochrome c content in mitochondria, and reduced activation of caspase-9 and -3 [29].

It was suggested that molecular targeting of the Apaf-1caspase-9 signalling pathway may be a feasible neuroprotective strategy to enhance the endogenous threshold for caspase activation and prevent neuronal loss in stroke [30]. It was showed that acetaminophen reduces apoptosis (and activation of caspase-9) in an in vivo model of cerebral ischemia-reperfusion [31].

It was demonstrated that agents that improve mitochondrial function or inhibit the permeability transition may eliminate increased caspase -3 and -9 activation and cell death associated with enhanced $N$-methyl-D-aspartate receptor (NMDAR) activity in Huntington's disease (HD) [32].

It is known that sera from $26 \%$ of patients with sporadic ALS induced in vitro apoptosis of a human neuroblastoma cell line. In mixed cultures of rat embryonic brain and spinal cord cells the sera from ALS patients induced the apoptosis of a subpopulation of motoneurons [33]. It was demonstrated that intrathecally infused TAT-fused protein was effectively transferred into spinal cord neurons of ALS transgenic mice, including motor neurons, and that intrathecal infusion of TAT-modified Bcl-X(L) delayed disease onset, prolonged survival, and improved motor performance. Histological studies show the attenuation of motor neuron loss and decrease in the number of cleaved caspase 9-, cleaved caspase 3-, and terminal deoxynucleotidyl transferase-mediated dUTP nick-end labeling (TUNEL)positive cells in the lumbar cords of TAT-modified Bcl$\mathrm{X}(\mathrm{L})$-treated G93A mice [34].

This study showed that the caspase-9 levels are significantly increased in the serum of the whole group of patients with ALS compared with those from the control group. This indicates that caspase- 9 is implicated in pathophysiology of ALS. It may be interesting to know caspase-9 levels also in the cerebrospinal fluid of patients with ALS but this measurement will be the subject of the next research. Caspase-9 levels were significantly increased in ALS patients with long duration of the disease, with severe clinical state, and with bulbar onset of ALS compared with controls but not in ALS patients with short duration of the disease, with mild clinical state, and with limb onset of ALS compared with controls. The correlation between serum caspase-9 and severity of clinical state of ALS patients, and the duration of the disease was statistically significant. This indicates that apoptosis is more advanced in patients with severe clinical state, bulbar onset, and a long duration of the disease. Moreover, it is known that patients with bulbar onset of ALS have more severe clinical state than patients with limb onset of the disease. Tokuda et al. [35] demonstrated that caspases are present in nonactive forms in the spinal cords of wild-type mice during the early stage of the disease. In transgenic mice, the caspases are present in their active forms. During the advanced stage of the disease, when paralysis is present, the active caspases levels are increased. Data from the recent study confirm this observation and suggest that caspase-9 plays a role in pathophysiology of ALS, and antiapoptotic therapy might be helpful in this disease.

Open Access This article is distributed under the terms of the Creative Commons Attribution Noncommercial License which permits any noncommercial use, distribution, and reproduction in any medium, provided the original author(s) and source are credited.

\section{References}

1. Okouchi M, Ekshyyan O, Maracine M, Aw TY (2007) Neuronal apoptosis in neurodegeneration. Antioxid Redox Signal 9(8):1059-1096

2. Caroppi P, Sinibaldi F, Fiorucci L, Santucci R (2009) Apoptosis and human diseases: mitochondrion damage and lethal role of released cytochrome $\mathrm{C}$ as proapoptotic protein. Curr Med Chem 16(31):4058-4065 
3. Kuida K (2000) Caspase-9. Int J Biochem Cell Biol 32(2):121-124

4. Sathasivam S, Ince PG, Shaw PJ (2001) Apoptosis in amyotrophic lateral sclerosis: a review of the evidence. Neuropathol Appl Neurobiol 27:257-274

5. Ekshyyan O, Aw TY (2004) Apoptosis: a key in neurodegenerative disorders. Curr Neurovasc Res 1(4):355-371

6. Hetz C, Thielen P, Fisher J, Pasinelli P, Brown RH, Korsmeyer S, Glimcher L (2007) The proapoptotic BCL-2 family member BIM mediates motoneuron loss in a model of amyotrophic lateral sclerosis. Cell Death Differ 14(7):1386-1389

7. Wenqenack TM, Holasek SS, Montano CM, Gregor D, Curran GL, Poduslo JF (2004) Activation of programmed cell death markers in ventral horn motor neurons during early presymptomatic stages of amyotrophic lateral sclerosis in a transgenic mouse model. Brain Res 1027:73-86

8. Wootz H, Hansson I, Korhonen L, Näpänkangas U, Lindholm D (2004) Caspase-12 cleavage and increased oxidative stress during motoneuron degeneration in transgenic mouse model of ALS. Biochem Biophys Res Commun 322(1):281-286

9. Guégan C, Vila M, Teismann P, Chen C, Onténiente B, Li M, Friedlander RM, Przedborski S (2002) Instrumental activation of bid by caspase- 1 in a transgenic mouse model of ALS. Mol Cell Neurosci 20(4):553-562

10. Barbosa LF, Cerqueira FM, Macedo AF, Garcia CC, Angeli JP, Schumacher RI, Sogayar MC, Augusto O, Carrì MT, Di Mascio $\mathrm{P}$, Medeiros MH (2010) Increased SOD1 association with chromatin, DNA damage, p53 activation, and apoptosis in a cellular model of SOD1-linked ALS. Biochem Biophys Acta 1802(5):462-471

11. Kong Q, Wang M, Liao Z, Camden JM, Yu S, Simonyi A, Sun GY, Gonzalez FA, Erb L, Seye CI, Weisman GA (2005) P2X(7) nucleotide receptors mediate caspase-8/9/3-dependent apoptosis in rat primary cortical neurons. Purinergic Signal 1:227-247

12. Nagata T, Ilieva H, Murakami T, Shiote M, Narai H, Ohta $Y$, Hayashi T, Shoji M, Abe K (2007) Increased ER stress during motor neuron degeneration in a transgenic mouse model of amyotrophic lateral sclerosis. Neurol Res 29(8):767-771

13. Inoue $H$, Tsukita $K$, Iwasato $T$, Suzuki $Y$, Tomioka M, Tateno M, Nagao M, Kawata A, Saido TC, Miura M, Misawa H, Itohara S, Takahashi R (2003) The crucial role of caspase-9 in the disease progression of a transgenic ALS mouse model. EMBO J 22(24):6665-6674

14. Miller JB, Girgenrath M (2006) The role of apoptosis in neuromuscular diseases and prospects for anti-apoptosis therapy. Trends Mol Med 12(6):279-286

15. Lavallard VJ, Bonnafous S, Patouraux S, Saint-Paul MC, Rousseau D, Anty R, Le Marchand-Brustel Y, Tran A, Gual P (2011) Serum markers of hepatocyte death and apoptosis are non invasive biomarkers of severe fibrosis in patients with alcoholic liver disease. PLoS One 6(3):e17599

16. Delogu G, Famularo G, Tellan G, Marandola M, Antonucci A, Signore M, Marcellini S, Moretti S (2008) Lymphocyte apoptosis, caspase activation and inflammatory response in septic shock. Infection 36(5):485-487

17. Agosto M, Azrin M, Singh K, Jaffe AS, Liang BT (2011) Serum caspase-3 p17 fragment is elevated in patients with ST-segment elevation myocardial infarction: a novel observation. J Am Coll Cardiol 57(2):220-221

18. Roth C, Pantel K, Müller V, Rack B, Kasimir-Bauer S, Janni W, Schwarzenbach H (2011) Apoptosis-related deregulation of proteolytic activities and high serum levels of circulating nucleosomes and DNA in blood correlate with breast cancer progression. BMC Cancer 11:4

19. Babas E, Ekonomopoulou MT, Karapidaki I, Doxakis A, Betsas G, Iakovidou-Kritsi Z (2010) Indication of participation of caspase-2 and caspase-5 in mechanisms of human cervical malignancy. Int J Gynecol Cancer 20(8):1381-1385

20. Brooks BR (1994) El Escorial Word Federation of Neurology criteria for the diagnosis of amyotrophic lateral sclerosis. J Neurol Sci 124(Suppl):96-107

21. Gordon PH, Miller RG, Moore DH (2004) ALSFRS-R. Amyotroph Lateral Scler Other Motor Neuron Disord 5:90-93

22. Darwish RS, Amiridze NS (2010) Detectable levels of cytochrome $\mathrm{C}$ and activated caspase- 9 in cerebrospinal fluid after human traumatic brain injury. Neurocrit Care 12(3):337-341

23. Andreoli V, Trecroci F, La Russa A, Valentino P, Condino F, Latorre V, Nisticò R, Pirritano D, Del Giudice F, Canino M, Cittadella R, Quattrone A (2009) CASP-9: a susceptibility locus for multiple sclerosis in Italy. J Neuroimmunol 210(1-2): 100-103

24. Yu WR, Baptiste DC, Liu T, Odrobina E, Stanisz GJ, Fehlings MG (2009) Molecular mechanisms of spinal cord dysfunction and cell death in the spinal hyperostotic mouse: implications for the pathophysiology of human cervical spondylotic myelopathy. Neurobiol Dis 33(2):149-163

25. Ranganathan S, Harmison GG, Meyertholen K, Pennuto M, Burnett BG, Fischbeck KH (2009) Mitochondrial abnormalities in spinal and bulbar muscular atrophy. Hum Mol Genet 18(1):27-42

26. Wang L, Liu YH, Huang YG, Chen LW (2008) Time-course of neuronal death in the mouse pilocarpine model of chronic epilepsy using Fluoro-Jade C staining. Brain Res 1241:157-167

27. Blandini F, Sinforiani E, Pacchetti C, Samuele A, Bazzini E, Zangaglia R, Nappi G, Martignoni E (2006) Peripheral proteasome and caspase activity in Parkinson disease and Alzheimer disease. Neurology 66(4):529-534

28. Miyoshi K, Ohyagi Y, Sakae N, Motomura K, Ma L, Taniwaki T, Furuya H, Tabira T, Kira J (2009) Enhancement of activation of caspases by presenilin 1 gene mutations and its inhibition by secretase inhibitors. J Alzheimer Dis 16(3):551-564

29. Imamura K, Takeshima T, Kashiwaya Y, Nakaso K, Nakashima K (2006) D-beta-hydroxybutyrate protects dopaminergic SHSY5Y cells in a rotenone model of Parkinson's disease. J Neurosci Res 84(6):1376-1384

30. Cao G, Xiao M, Sun F, Xiao X, Pei W, Li J, Graham SH, Simon RP, Chen J (2004) Cloning of a novel Apaf-1-interacting protein: a potent suppressor of apoptosis and ischemic neuronal cell death. J Neurosci 24(27):6189-6201

31. Baliga SS, Jaques-Robinson KM, Hadzimichalis NM, Golfetti R, Merrill GF (2010) Acetaminophen reduces mitochondrial dysfunction during early cerebral postischemic reperfusion in rats. Brain Res 1319:142-154

32. Zeron MM, Fernandes HB, Krebs C, Shehadeh J, Wellington CL, Leavitt BR, Baimbridge KG, Hayden MR, Raymond LA (2004) Potentiation of NMDA receptor-mediated excitotoxicity linked with intrinsic apoptotic pathway in YAC transgenic mouse model of Huntington's disease. Mol Cell Neurosci 25(3):469-479

33. Yi FH, Lautrette C, Vermont-Desroches S, Bordessoule D, Couratier P, Wijdenes J, Preud'homme JL, Jauberteau MO (2000) In vitro induction of neuronal apoptosis by anti-Fas antibodycontaining sera from amyotrophic lateral sclerosis patients. J Neuroimmunol 109:211-220

34. Ohta Y, Kamiya T, Nagai M, Nagata T, Morimoto N, Miyazaki K, Murakami T, Kurata T, Takehisa Y, Ikeda Y, Asoh S, Ohta S, Abe K (2008) Therapeutic benefits of intrathecal protein therapy in a mouse model of amyotrophic lateral sclerosis. J Neurosci Res 86(13):3028-3037

35. Tokuda E, Ono S, Ishige K, Watanabe S, Okawa E, Ito Y, Suzuki $\mathrm{T}$ (2007) Dysequilibrium between caspases and their inhibitors in a mouse model for amyotrophic lateral sclerosis. Brain Res 1148:234-242 